Available online at GSC Online Press Directory

GSC Biological and Pharmaceutical Sciences

e-ISSN: 2581-3250, CODEN (USA): GBPSC2

Journal homepage: https://www.gsconlinepress.com/journals/gscbps

(RESEARCH ARTICLE)

\title{
Essential oil compositions and antioxidant properties of Cycas revoluta (Thunb.)
}

\author{
Anifalaje Eniola Olabisi ${ }^{1, *}$ and Odeja Oluwakayode Olubunmi ${ }^{2}$ \\ 1 Department of Chemistry, University of Ibadan, Ibadan, Oyo State, Nigeria. \\ 2 Department of Chemistry, Federal University of Petroleum Resources, Effurun, Delta State, Nigeria.
}

Publication history: Received on 28 October 2019; revised on 13 November 2019; accepted on 14 November 2019

Article DOI: https://doi.org/10.30574/gscbps.2019.9.2.0203

\begin{abstract}
Cycas revoluta is an ornamental plant which has had some of its parts used in treating some forms of cancers, relieving headaches, giddiness and sore throat. Essential oils from both fresh and air-dried C. revoluta leaf and stalk samples were obtained by hydro-distillation using a Clevenger apparatus with the constituents identified and quantified by Gas Chromatography - Mass Spectrometry (GC-MS) analysis. The fresh leaf and stalk essential oils had 22 and 45 identified essential oil components respectively while the air-dried parts had 25 leaf essential oil and 18 stalk essential oil components. $\gamma$-ketovaleric acid (29.36 \%), 2,4,4-Trimethyl-2-pentene (13.27\%), lauric acid (9.84 \%) and 7Nonenamide (58.71\%) constituted the major components of the fresh leaf, fresh stalk, dry leaf and dry stalk essential oils respectively. Free radical scavenging ability of the essential oils was assayed with 1,1-diphenyl-2-picrylhydrazyl (DPPH) free radical scavenging method and the four essential oil samples recorded anti-oxidant activities which were concentration dependent with the dry leaf essential oil exhibiting the highest activity at $1 \mathrm{mg} / \mathrm{mL}$ with a $72 \%$ inhibition. These values were comparable with the currently known antioxidant standards.
\end{abstract}

Keywords: Antioxidant assay; Cycas revoluta; DPPH; essential oils; GC-MS; Hydro-distillation

\section{Introduction}

Cycas revoluta (Thunb) is the only known genus of the family, Cycadaceae. It is a popular ornamental plant known as sago or long sago palm $[1,2]$. The species could be found throughout the world although this cold hardy palm is native to the Far East. Cycas revoluta (Thunb) has become very popular for indoor decorations and has also been used for outside landscaping for centuries.

The seeds are used in China as an anti-rheumatic, expectorant and a tonic. The shoots are utilised as an astringent and diuretic $[1,2]$. The young leaves are edible and the juice of tender leaves is valuable for the treatment of flatulence and vomiting [3]. It has also been used to relief headaches, giddiness and sore throat. C. revoluta appears to be the most studied followed by-C. circinalis due to their chemical constituents and biological activities. Both have been found to contain toxin, cycasin - an azoxy-glucoside that is carcinogenic [4]. Biflavonoids, lignans, flavan-3-ols, flavone-cglucosides, nor-isoprenoids and flavanone have been isolated from the chloroform extract of C. revoluta. The bioflavonoids exhibited moderate activity against Subtilis aureus and methicillin-resistant Subtilis aureus [5]. The presence of saponins, tannins and sugars in the chloroform and hydro-alcoholic extracts of $C$. revoluta leaves has also been reported [6].

Estragole was reported to be the primary volatile compound in the male and female cones of $C$. revoluta [7]. Leaves of C. revoluta afforded lariciresinol, naringenin and flavonoids which are derivatives of amento-flavone and hinoki-flavone. The anti-microbial, anti-malarial and anti-leshmanial activities of these compounds have also been reported [8]. A tincture of $C$. revoluta leaves has been reported to contain inhibitors of cytochrome P-450 aromatase [9] and thus may

\footnotetext{
${ }^{*}$ Corresponding author

E-mail address: eanifalaje4911@stu.ui.edu.ng
} 
be efficacious in treating oestrogen-dependent carcinoma. The essential oils from $C$. revoluta have not however been analysed or reported to the best of our knowledge. This paper focuses on identification of the chemical constituents and antioxidant properties of the essential oils from the fresh and dry leaves and stalk of C. revoluta.

\section{Material and methods}

\subsection{Plant materials}

Fresh leaves and stalks of $C$. revoluta samples were collected from the Botany Department environs of the University of Ibadan in August, 2018. A voucher specimen with voucher number FHI 6013157596 was deposited at the Herbarium of the Forest Research Institute of Nigeria (FRIN), Ibadan where the plant was identified and authenticated.

\subsection{Isolation of essential oils}

The fresh plant samples were immediately chopped while the air-dried samples were air-dried for 7 days and pulverised. Both the freshly chopped and air-dried samples were subjected to hydro-distillation for the extraction of essential oils. Essential oil from each plant part was separately isolated for three hours using an all-glass-clevenger-type apparatus according to the British Pharmacopoeia specifications [10]. The oil yields were calculated and thereafter, the oils were stored in vials in the refrigerator at about $4^{\circ} \mathrm{C}$ prior analysis.

\subsection{Gas Chromatography-Mass Spectrometry (GC-MS) Analysis}

Perkin Elmer Gas Chromatography (Clarus 580) equipped with MSD mass spectrometer (Clarus SQ8S) instrument with built-in auto sampler was used in identifying the chemical constituents of the volatile oils. Capillary column type was an Elite-5MS (30.0 m $\times 0.25 \mathrm{~mm}$ id $\times 0.25 \mu \mathrm{m})$. Gas Chromatographic (GC) operating conditions were as follows: a sample volume of $1.0 \mu \mathrm{L}$ was injected in helium carrier gas at a split flow of $20 \mathrm{~mL} / \mathrm{min}$; column temperature was programmed from $37-320^{\circ} \mathrm{C}$ at a rate of $18-25{ }^{\circ} \mathrm{C} / \mathrm{min}$ and held for 0.5 and 1.85 mins at 18 and $320{ }^{\circ} \mathrm{C}$ respectively. The injector temperature was $250{ }^{\circ} \mathrm{C}$ and MS Ion source temperature was $280{ }^{\circ} \mathrm{C}$ with full scan and solvent delay of $0-2.30$ min. MS Scan range was $\mathrm{m} / \mathrm{z} 35-500$ in $0.10 \mathrm{sec}$.

Individual constituents of the oil were identified based on their retention indices and their mass spectral fragmentation patterns. The NIST 11.L database/ChemStation data system was used to acquire the mass spectral data and compared with published data [11]. The GC retention index data were also compared with literature values.

\subsection{Antioxidant assay}

The method of Bruits [12] was adopted and modified for the investigation of the DPPH scavenging activity of the essential oils. Five concentrations of the volatile oils (1-0.015) mg/mL were measured in test tubes; $0.1 \mathrm{mM}$ methanol solution of DPPH ( $2 \mathrm{~mL}$ ) was added to each test tube and vigorously shaken. The mixture was then incubated at room temperature for 30 minutes. The absorbance of the treated essential oil samples at different concentrations and the blank DPPH solution (control) were thereafter measured at $517 \mathrm{~nm}$ with the aid of a UV/Visible spectrometer (GS-UV12 spectrometer). Butylated hydroxyl anisole (BHA) and $\alpha$ - tocopherol which are established anti-oxidants were used as standards. The analyses were carried out in triplicates and the average values were obtained [13-16]. The activities of all the analysed samples were calculated as a function of their \% inhibition using the equation:

$\%$ Inhibition $\frac{\text { Acontrol - Asample }}{\text { Acontrol }} \times 100$

The results were expressed as mean \pm standard deviation of three parallel measurements. Microsoft Office excel, 2007 software was used to plot the graph.

\section{Results and discussion}

\subsection{Properties and composition of C.revoluta essential oils}

Fresh leaf, fresh stalk and dry leaf essential oils of $C$. revoluta gave leafy odours while the dry stalk essential oil had a woody scent. The fresh leaf essential oil was pale white in colour; the fresh stalk was pale green in colour while the essential oils from the dry samples were colourless. Dry C. revoluta leaf-stalk essential oil had the highest yield $(0.57$ $\% \mathrm{w} / \mathrm{w}$ ) while the fresh leaf, fresh leaf-stalk and dry leaf essential oils yielded $0.20,0.42$ and $0.50 \%$ (w/w) respectively. 
Individual constituents of the oils were identified by GC-MS based on the comparison of their mass spectral fragmentation patterns using the NIST 11.L database/ChemStation data system and comparison of their retention indices by with published spectra. Twenty two and forty five components were identified in the fresh leaf and stalk essential oils while twenty five and eighteen components were identified in the air-dried leaf and stalk essential oil samples by GC/MS analysis as displayed in Tables 1.

Table 1 Compounds obtained from GC-MS analysis of fresh C. revoluta leaf and leaf- stalk essential oils

\begin{tabular}{|c|c|c|c|c|c|c|}
\hline \multirow{2}{*}{$\begin{array}{l}\text { Peak } \\
\text { No }\end{array}$} & \multirow{2}{*}{$\begin{array}{l}\text { Retention } \\
\text { Index }\end{array}$} & \multirow{2}{*}{ Identified Compounds } & \multicolumn{4}{|c|}{ Composition (\%) } \\
\hline & & & fCrL & dCrL & fCrS & dCrS \\
\hline 1 & 690 & 2-Methyl-3-pentanone & 1.44 & 3.09 & - & 0.34 \\
\hline 2 & 717 & 2,4,4-Trimethyl-2-pentene & 4.32 & - & 13.27 & - \\
\hline 3 & 742 & 3-Methylhept-1-ene & - & - & 2.81 & - \\
\hline 4 & 780 & 2-Hexanol & 2.62 & - & - & - \\
\hline 5 & 788 & 2-Methyl-3-ethylhexane & - & - & 0.98 & - \\
\hline 6 & 794 & Toluene & 4.32 & - & 5.95 & - \\
\hline 7 & 816 & (2E)-3,4,4-Trimethyl-2-hexene & - & - & 0.43 & - \\
\hline 8 & 824 & Dimethylfulvene & - & 5.31 & - & - \\
\hline 9 & 842 & 1,trans-2-Dimethylcyclohexane & - & - & 7.37 & - \\
\hline 10 & 851 & 3,4-Dimethyl-2-hexanol & - & - & 0.43 & - \\
\hline 11 & 868 & 3,3-Dimethyl-2-hexanone & - & - & 2.18 & - \\
\hline 12 & 887 & 2,7-Dimethyloctane & - & 1.89 & 1.23 & - \\
\hline 13 & 907 & m-Xylene & - & 3.22 & 3.00 & - \\
\hline 14 & 912 & Butenediol & 1.81 & - & - & - \\
\hline 15 & 914 & 3-Hexyl hydroperoxide & 3.42 & - & - & - \\
\hline 16 & 935 & 1-Chloro-3-methyl-3-pentanol & 1.70 & - & - & - \\
\hline 17 & 953 & (1E)-1-Chloro-4,4-dimethyl-1-penten-3-one & - & 4.92 & - & - \\
\hline 18 & 969 & cis-3-Methylcyclohexanol & - & 4.49 & - & - \\
\hline 19 & 1006 & m-Methylethylbenzene & - & - & 1.39 & - \\
\hline 20 & 1011 & gamma.-Ketovaleric acid & 29.36 & - & 1.87 & - \\
\hline 21 & 1044 & 2-hydroxy-2-methyl-4-heptanone & 1.45 & - & - & - \\
\hline 22 & 1066 & 2-Isopropyl-5-methyl-1-hexanol & - & 2.56 & 1.05 & - \\
\hline 23 & 1086 & 2,9-Dimethyldecane & - & 8.77 & - & 2.14 \\
\hline 24 & 1115 & 5-Octanol-4-one & 1.75 & - & - & - \\
\hline 25 & 1150 & 4-Hydroxy-3-propyl-2-hexanone & 2.96 & - & - & - \\
\hline 26 & 1164 & $(1 \mathrm{~S}, 2 \mathrm{R}, 5 \mathrm{R})-(+)-$ Isomenthol & - & - & 3.30 & - \\
\hline 27 & 1185 & 3,8-Dimethylundecane & - & 1.60 & - & - \\
\hline 28 & 1190 & Phenethyl alcohol & 6.02 & - & - & - \\
\hline 29 & 1249 & 5-Propyldecane & - & 1.42 & - & - \\
\hline 30 & 1320 & 2,6,11-Trimethyldodecane & 4.80 & - & - & 1.29 \\
\hline 31 & 1322 & 5-Bromo-2-adamantanone & - & - & 0.72 & - \\
\hline 32 & 1333 & 7-Nonenamide & - & - & - & 58.71 \\
\hline 33 & 1365 & 1-Iodo-2-methylnonane & - & - & 1.61 & - \\
\hline 34 & 1389 & 3-Cyclohexylpropanamide & - & - & - & 0.54 \\
\hline 35 & 1402 & Lauraldehyde & - & - & 1.10 & - \\
\hline
\end{tabular}


Anifalaje and Odeja / GSC Biological and Pharmaceutical Sciences 2019, 09(02), 102-109

\begin{tabular}{|c|c|c|c|c|c|c|}
\hline 36 & 1471 & Allyl caprate & 1.59 & 5.02 & - & - \\
\hline 37 & 1483 & 2-Methyl-6-propyldodecane & - & - & - & 0.99 \\
\hline 38 & 1484 & 4-epi-cubedol & - & 2.52 & - & - \\
\hline 39 & 1490 & $\begin{array}{l}\text { 1,2,3,5,6,7,8,8a-octahydro-1,4-dimethyl-7-(1- } \\
\text { methylethenyl)- Azulene }\end{array}$ & - & - & 1.21 & - \\
\hline 40 & 1519 & 2,6,10-Trimethyltetradecane & - & 3.35 & - & - \\
\hline 41 & 1530 & Viridiflorol & - & - & 0.79 & - \\
\hline 42 & 1555 & 3,5-Di-tert-butylphenol & - & - & 0.41 & - \\
\hline 43 & 1564 & 1-Iodo-2-methylundecane & - & 1.60 & - & - \\
\hline 44 & 1574 & beta.-Humulene & - & - & 8.64 & 2.42 \\
\hline 45 & 1580 & alpha.-Cadinol & - & 2.80 & - & 2.00 \\
\hline 46 & 1575 & 1,2-Dicyclohexylpropane & - & - & 0.68 & - \\
\hline 47 & 1612 & n-Cetane & - & - & 0.49 & - \\
\hline 48 & 1616 & Tumerone & - & - & 1.25 & - \\
\hline 49 & 1668 & 4,6-di-tert-Butyl-m-cresol & - & - & - & 0.90 \\
\hline 50 & 1701 & n-Pentadecanal & - & - & 1.94 & \\
\hline 51 & 1753 & Crocetane & 3.36 & - & 2.61 & 0.65 \\
\hline 52 & 1754 & Hexahydrofarnesyl acetone & 4.58 & - & 1.52 & - \\
\hline 53 & 1770 & 2-Ethyl-2-methyl-1-tridecanol & - & - & 0.46 & 0.27 \\
\hline 54 & 1771 & (6Z,9Z)-6,9-Pentadecadien-1-ol & - & - & 1.93 & - \\
\hline 55 & 1808 & Z-9-Hexadecenal & 2.29 & - & 2.35 & - \\
\hline 56 & 1822 & Myristic amide & - & - & - & 14.12 \\
\hline 57 & 1843 & (8Z)-14-Methyl-8-hexadecenal & - & - & 5.53 & - \\
\hline 58 & 1846 & 2-Methyloctadecane & - & - & 0.95 & - \\
\hline 59 & 1852 & 2,6,10,14-Tetramethylheptadecane & 2.73 & - & - & 0.30 \\
\hline 60 & 1680 & Methyl myristate & - & - & 1.29 & - \\
\hline 61 & 1924 & Palmitic acid chloride & - & - & 0.40 & - \\
\hline 62 & 1930 & Myristyl monoethoxylate & - & 4.01 & - & - \\
\hline 63 & 1945 & 9-Methylnonadecane & - & - & 2.23 & - \\
\hline 64 & 1976 & (2E)-2-Hexadecenoic acid & - & 2.20 & - & - \\
\hline 65 & 1978 & $\begin{array}{l}\text { [3R- } \\
\text { (3.alpha.,4a.beta.,6a.alpha.,10a.beta.,10b.alpha.)]- } \\
\text { 3-ethenyldodecahydro-3,4a,7,7,10a-pentamethyl- } \\
\text { 1H-Naphtho[2,1-b]pyran }\end{array}$ & - & - & 0.46 & - \\
\hline 66 & 2009 & Eicosane & - & - & 4.33 & - \\
\hline 67 & 2021 & Palmitamide & - & - & - & 4.38 \\
\hline 68 & 2026 & Hexadecyl iodide & - & - & 1.42 & - \\
\hline 69 & 2045 & 3,7,11,15-Tetramethyl-2-hexadecen-1-ol & 6.28 & 1.92 & 1.26 & 2.09 \\
\hline
\end{tabular}




\begin{tabular}{|c|c|c|c|c|c|c|}
\hline 70 & 2054 & Lauric acid & & 9.84 & - & - \\
\hline 71 & 2109 & Heneicosane & - & - & 1.28 & - \\
\hline 72 & 2119 & Isobutyl .alpha.-methylacrylate & - & 3.93 & - & - \\
\hline 73 & 2127 & $\begin{array}{l}\text { 2,2-Dimethyl-6-methylene-1-[3,5-dihydroxy-1- } \\
\text { pentenyl]cyclohexan-1-perhydrol }\end{array}$ & 2.24 & - & - & - \\
\hline 74 & 2144 & $\begin{array}{l}\text { 2.alpha.,3.alpha.-epithio-17.alpha.-methyl-5.alpha.- } \\
\text { androstan-17.beta.-ol }\end{array}$ & 2.86 & - & - & - \\
\hline 75 & 2190 & Verticiol & 7.56 & - & - & - \\
\hline 76 & 2192 & trans-Geranylgeraniol & - & - & 0.44 & - \\
\hline 77 & 2211 & Thunbergol & - & - & 0.43 & - \\
\hline 78 & 2225 & 1-Iodooctadecane & - & 2.80 & - & - \\
\hline 79 & 2243 & 2-Methyldocosane & - & 3.06 & - & - \\
\hline 80 & 2422 & 4-(3,5-Di-tert-butyl-4-hydroxyphenyl)butyl acrylate & - & 4.06 & - & - \\
\hline 81 & 2542 & 11-Butyldocosane & - & - & - & 0.48 \\
\hline 82 & 2561 & $\begin{array}{l}\text { 2-[4-methyl-6-(2,6,6-trimethylcyclohex-1- } \\
\text { enyl)hexa-1,3,5-trienyl]cyclohex-1-en-1- } \\
\text { carboxaldehyde }\end{array}$ & - & - & - & 2.75 \\
\hline 83 & 2641 & 2-methylhexacosane & - & - & - & 0.61 \\
\hline 84 & 2714 & 4,4-Dimethylcholest-7-en-3-one & - & - & 0.78 & - \\
\hline 85 & 2840 & 2-methyloctacosane & - & - & 1.35 & - \\
\hline 86 & 2944 & Andrographolid & - & 3.83 & - & - \\
\hline 87 & 3493 & 3,5,6,12-Tetrahydroxyergostan-25-yl acetate & - & - & 0.78 & - \\
\hline 88 & 4339 & 1-Hentetracontanol & - & 2.31 & - & - \\
\hline 89 & Unidentified & & 4.87 & - & 0.53 & 2.52 \\
\hline & Total $^{7}$ & & 99.53 & 90.52 & 93.82 & 97.5 \\
\hline
\end{tabular}

Peak number: as eluted on GC column with Elite-5MS (30 m x $0.25 \mathrm{~mm}$ id x $0.25 \mu \mathrm{m})$. Programmed temperature from 37 to $320{ }^{\circ} \mathrm{C}$ at $18-25{ }^{\circ} \mathrm{C} / \mathrm{min}$ in a split mode with helium stationary phase

fCrL: fresh Cycas revoluta leaves; dCrL: dry Cycas revoluta leaves; fCrS: fresh Cycas revoluta stalk; dCrS: dry Cycas revoluta stalk

The fresh leaf, fresh stalk, dry leaf and dry stalk volatile oils were observed to consist mainly of hydrocarbons (62.43, $54.96,78.81$ and $70.85 \%$ respectively). Of the classes of terpenes possible, monoterpenes, diterpenes, sesquiterpenes, triterpenes and aprocarotenoids were observed. Monoterpenes were present in abundance of $6.02,2.84$ and $2.56 \%$ in the fresh leaf, fresh stalk and dry leaf essential oils respectively while no monoterpene was identified in the dry leaf essential oil. For the fresh leaf, fresh stalk, dry leaf and dry stalk essential oils, an abundance of 4.80, 23.54, 10.64 and $6.61 \%$ were identified as sesquiterpenes while abundance of $22.79,11.39,3.83$ and $14.77 \%$ were identified as diterpenes respectively. Of all the essential oils, only the fresh Cycas revoluta leaf essential oil had triterpenes (2.13\%) present and dry Cycas revoluta stalk essential oil had an apocarotenoid (2.75\%) present.

Y-Ketovaleric acid (29.36\%), 2, 4, 4- Trimethyl-2-pentene (13.27 \%), 2.9- Dimethylundecane (8.77 \%) and 7Nonenamide (58.71\%) which are all hydrocarbons were respectively identified as the most abundant components in the fresh leaf, fresh stalk, dry leaf and dry stalk essential oils. Verticiol, a diterpene was the most abundant terpene (7.56 $\%)$ in the fresh leaf essential oil; beta-Humulene, a sesquiterpene was the most abundant terpene (8.64 \%) in the fresh leaf essential oil while Andrographolid (3.83 \%) and Capramide (14.12\%) which are diterpenes were the most abundant terpenes in the dry leaf and dry stalk essential oils respectively.

\subsection{Antioxidant activity}

1, 1-diphenyl-2-picrylhydrazyl (DPPH) was used in measuring the antioxidant activity of the essential oil samples. Free radical scavenging activities of the samples are as shown in Table 3 while the graphical representation of the activity is depicted in Figure 1. 
Table 2 Absorbance values for DPPH free radical scavenging activity of essential oils of the fresh leaf, fresh leaf-stalk, dry leaf, and dry leaf-stalk of Cycas revolute

\begin{tabular}{|c|c|c|c|c|c|c|}
\hline $\begin{array}{l}\text { Concentration } \\
(\mathrm{mg} / \mathrm{mL})\end{array}$ & Fresh leaf & Dry leaf & $\begin{array}{l}\text { Fresh Leaf- } \\
\text { stalk }\end{array}$ & Dry Leaf-stalk & BHA & $\alpha-$ Tocopherol \\
\hline 1.0 & $0.633 \pm 7.07 \mathrm{e}-4$ & $0.322 \pm 0$ & $0.681 \pm 0$ & $0.652 \pm 0$ & $0.066 \pm 1 \times 10^{-3}$ & $0.640 \pm 1 \times 10^{-3}$ \\
\hline 0.5 & $0.670 \pm 7.07 \mathrm{e}^{-4}$ & $0.405 \pm 0$ & $0.685 \pm 7.07 \mathrm{e}^{-4}$ & $0.660 \pm 7.07 \mathrm{e}^{-4}$ & $0.074 \pm 1 \times 10^{-3}$ & $0.657 \pm 1 \times 10^{-3}$ \\
\hline 0.25 & $0.682 \pm 0$ & $0.441 \pm 1.414 \mathrm{e}^{-3}$ & $0.691 \pm 7.07 \mathrm{e}^{-4}$ & $0.695 \pm 7.07 \mathrm{e}^{-4}$ & $0.063 \pm 1.1 \times 10^{-3}$ & $0.663 \pm 2 \times 10^{-3}$ \\
\hline 0.125 & $0.691 \pm 7.07 \mathrm{e}^{-4}$ & $0.449 \pm 7.07 \mathrm{e}^{-4}$ & $0.698 \pm 7.07 \mathrm{e}^{-4}$ & $0.671 \pm 0$ & $0.078 \pm 1.1 \times 10^{-3}$ & $0.672 \pm 2 \times 10^{-3}$ \\
\hline 0.0625 & $0.704 \pm 7.07 \mathrm{e}^{-4}$ & $0.504 \pm 7.07 \mathrm{e}^{-4}$ & $0.717 \pm 7.07 \mathrm{e}^{-4}$ & $0.719 \pm 0$ & $0.072 \pm 1 \times 10^{-3}$ & $0.681 \pm 2 \times 10^{-3}$ \\
\hline 0.03125 & $0.716 \pm 7.07 \mathrm{e}^{-4}$ & $0.495 \pm 1.414 \mathrm{e}^{-3}$ & $0.807 \pm 7.07 \mathrm{e}^{-4}$ & $0.721 \pm 1.414 \mathrm{e}^{-3}$ & $0.082 \pm 1 \times 10^{-3}$ & $0.692 \pm 2 \times 10^{-3}$ \\
\hline 0.015625 & $0.731 \pm 7.07 \mathrm{e}^{-4}$ & $0.518 \pm 7.07 \mathrm{e}^{-4}$ & $0.928 \pm 7.07 \mathrm{e}^{-4}$ & $0.568 \pm 7.07 \mathrm{e}^{-4}$ & $0.078 \pm 1 \times 10^{-3}$ & $0.700 \pm 2 \times 10^{-3}$ \\
\hline
\end{tabular}

BHA: Butylated Hydroxyl anisole

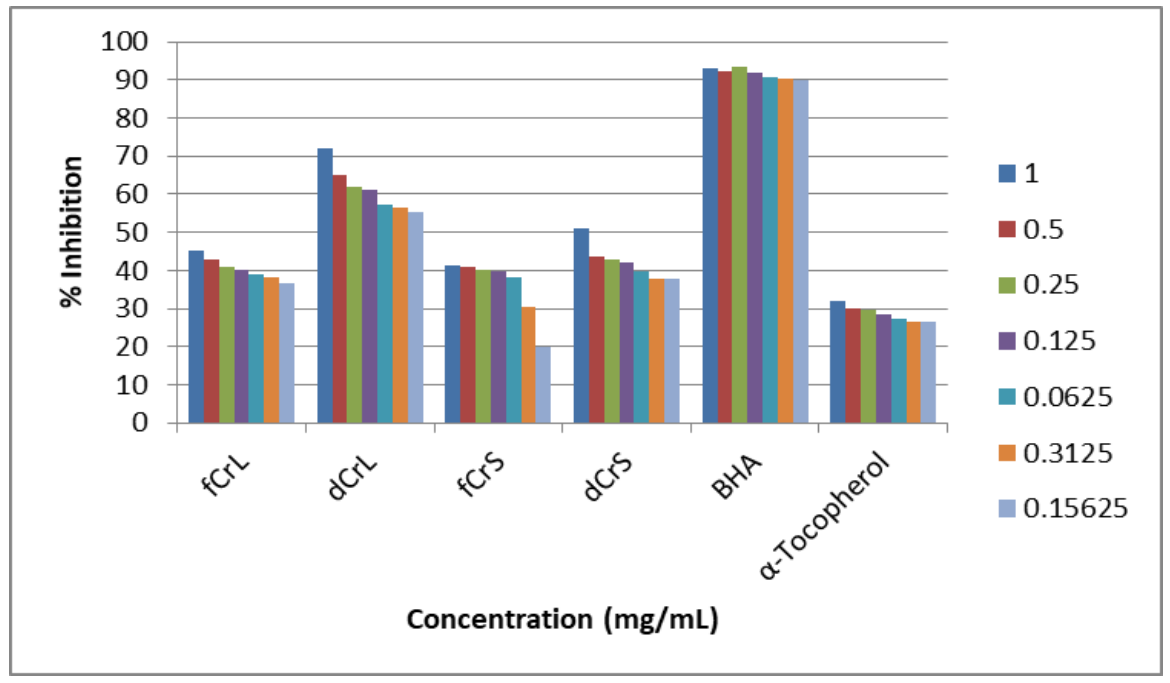

Figure 1 DPPH radical scavenging activity of essential oils and standards at 1.0, 0.5, 0.25, 0.125 mg/mL. $\alpha$-tocopherol and BHA (Butylated Hydroxyl Anisole) are the standards; fCrL: fresh Cycas revoluta leaves; dCrL: dry Cycas revoluta leaves; fCrS: fresh Cycas revoluta stalk; dCrS: dry Cycas revoluta stalk

Potential antioxidant activities were demonstrated by the essential oils at all concentrations. The potency of these volatile oils was generally concentration dependent with their potency generally reducing as the concentration was reduced including for BHA and $\alpha$-tocopherol. Dry $C$. revoluta leaf-essential oil had the highest activity at all concentrations used when compared with essential oil samples from other parts with percentage inhibition (\% I) values ranging from $72.0-55.22 \%$ at $1.0-0.015625 \mathrm{mg} / \mathrm{mL}$. The DPPH radical scavenging activity at $0.5 \mathrm{mg} / \mathrm{mL} \mathrm{showed} \mathrm{the}$ fresh $C$. revoluta stalk-essential oil to be the least active (40.88 \%). Dry C. revoluta leaf-essential oil (61.88 \%) and dry C. revoluta-stalk-essential oil (42.95\%) were the most active at $0.25 \mathrm{mg} / \mathrm{mL}$ with fresh C. revoluta leaf essential oil (41.05 \%) with fresh Cycas revoluta stalk essential oil (40.27\%) being the least active at the same concentration. A similar progression as stated above was observed at concentrations $0.125,0.0625,0.03125$ and $0.015625 \mathrm{mg} / \mathrm{mL}$ where the dry C. revoluta leaf essential oil had the highest inhibition followed by the dry C. revoluta stalk essential oil, the fresh C. revoluta leaf essential oil and then the fresh $C$. revoluta stalk essential oil. All the afore-mentioned essential oils had activities higher than $\alpha$-tocopherol except for fresh Cycas revoluta stalk essential oil at $0.15625 \mathrm{mg} / \mathrm{mL}$ with an inhibition of $19.77 \%$ but lower activities than butylated hydroxylanisole (BHA) at all concentrations. 


\section{Conclusion}

The essential oils from each plant part differ qualitatively and quantitatively as portrayed by Gas Chromatography-Mass Spectrometer (GC-MS). A total of 22, 45, 25 and 18 components were identified in the fresh leaf, fresh stalk, dry leaf and dry stalk essential oils respectively. 3, 7,11, 15-Tetramethyl-2-hexadecen-1-ol was present in fresh leaf, fresh stalk, dry leaf and dry stalk essential oils at concentrations of 6.28, 1.92, 1.26 and $2.09 \%$ respectively. The identified components of the volatile oils could help explain their antioxidant properties. The four volatile oils exhibited good free radical scavenging properties with dry $C$. revoluta leaf-essential oil being the most promising free radical scavenger and at 1 $\mathrm{mg} / \mathrm{mL}$ with an inhibition of $72.0 \%$. The antioxidant activities could be a result of synergetic effect of all the identified components. These active samples on subjecting to further tests and analyses could be found to be better and safer agents compared with the synthetic standards currently in use.

\section{Compliance with ethical standards}

\section{Acknowledgments}

The authors profoundly thank Professor Olusegun O. Ekundayo for supervising this research work as part of the PhD research work of the corresponding author.

The authors thank Dr G.K. Oloyede and Miss Ufuoma Oghenejoboh of Chemistry Department, Faculty of Science, University of Ibadan, for their assistance with the requisite apparatus and antioxidant assay required for this research.

This research did not receive any specific grant from funding agencies in the public, commercial or not-for-profit sectors.

\section{Disclosure of conflict of interest}

The authors declare no conflict of interest.

\section{References}

[1] Duke J and Ayensu E. (1985). Medicinal plants of China. Reference Publications, 1. Algonac, Michigan, 960.

[2] Duke J. (1985). CRC handbook of medicinal herbs. CRC Press, Boca Raton, Florida, 677.

[3] Chopra R, Nayar S and Chopra I. (1986). Glossary of Indian medicinal plants (including the supplement). Council Scientific Industrial Research, New Delhi, 330.

[4] Nishida K, Kobayashi A and Nagahama T. (1955). Studies on cycasin, a new toxic glycoside, of Cycas revoluta Thunb. Bulletin of the Chemical Society of Japan, 19(1), 77-84.

[5] Moawad A, Hetta M, Zjawiony J, Jacob M, Hifnawy M, Marais J and Ferreira D. (2010). Phytochemical investigation of Cycas circinalis and Cycas revoluta leaflets moderately active antibacterial biflavonoids. Planta Medica, 76(8), 796-802.

[6] Manoj K, Mourya, Archana P, Ajay S, Gautam K and Abhishek M. (2011). Leaves of Cycas revoluta: potent antimicrobial and antioxidant agent. World Journal of Science, Technology and Sustainable Development, 1(10), 11-20.

[7] Hiroshi A and Masumi K. (2006). Estragole (4-allylanisole) is the primary compound in volatiles emitted from the male and female cones of Cycas revoluta, Journal of Plant Sciences, 119(6), 671-676.

[8] Ferreira D, Zjawiony J, Moawad A, Hifnawy M and Hetta M. (2009). Chemical investigation of two species of the Family Cycadaceae. Planta Medica, 75, 53-58.

[9] British Pharmacoepia 2. HMSO, London. 109.

[10] Kowalska M, Itzhak Y and Puett D. (1995). Presence of aromatase inhibitors in Cycads. Journal of Ethnopharmacology, 47(3), 113-116.

[11] Adams. (2007). Identification of Essential Oil Components By Gas Chromatography/Mass Spectrometry. 4th Edition. Allured Pub Corporation, 804.

[12] Bruits M and Bucar F. (2000). Anti-oxidant activity of Nigella sativa essential oils. Phytotherapy research, 14, 323-328. 
[13] Ayoola G, Coker H, Adesegun S, Adepoju-Bello A, Obaweya K, Ezennna E and Atangbayula T. (2008). Phytochemical screening and antioxidant activities of some selected medicinal plants used for malaria therapy in southwestern Nigeria. Tropical Journal of Pharmaceutical Research, 7, 1019-24.

[14] Koleva II, Van Beek T, Linssen J, de Groot A and Evstatieva L. (2002). Screening of plant extracts for antioxidant activity: a comparative study on three testing methods. Phytochemical Analysis, 13, 8-17.

[15] Masuda T, Inaba Y, Maekawa T, Takeda Y, Yamaguchi H, Nakamoto K, Kuninaga H, Nishizato S and Nonaka A. (2003). Simple detection method of powerful antiradical compounds in the raw extract of plants and its application for the identification of antiradical plant constituents. Journal of Agricultural and Food Chemistry, 51(7), 1831-1838.

[16] Saleh F, Hashem M, Moharam A and Zaied A. (2010). Efficacy of essential oils in the control of cumin root rot disease caused by Fusarium spp. Crop protection. 29, 295-299.

\section{How to cite this article}

Anifalaje EO and Odeja 00. (2019). Essential oil compositions and antioxidant properties of Cycas revoluta (Thunb.). GSC Biological and Pharmaceutical Sciences, 9(2), 102-109. 